\title{
SYNTHESIS, CHARACTERIZATION, AND EVALUATION OF ANTIBACTERIAL AND ANTIDEPRESSANT ACTIVITIES OF NOVEL TETRASUBSTITUTED IMIDAZOLE DERIVATIVES
}

\author{
AKSHAY MURALI ${ }^{*}$, ANUSHA SHAJI ${ }^{2}$ \\ ${ }^{1}$ Department of Pharmaceutical Chemistry, Malik Deenar College of Pharmacy, Kasaragod, Kerala, India. ${ }^{2}$ Department of Pharmacology, \\ Nirmala College of Pharmacy, Muvattpuzha, Kerala, India. Email: murali.akshay6@gmail.com
}

Received: 30 June 2019, Revised and Accepted: 01 August 2019

\section{ABSTRACT}

Objective: The objective of this study is to synthesize 10 novel tetrasubstituted imidazole derivatives and characterizations of them and to evaluate their antibacterial and antidepressant activities.

Methods: Ten novel tetrasubstituted imidazole derivatives were synthesized on the basis of Radziszewski imidazole synthesis. They were purified by double crystallization, characterized by melting point, thin-layer chromatography, infrared, and nuclear magnetic resonance spectroscopy, and subjected to elemental analysis. They were evaluated for their antibacterial activity by agar disc diffusion method and antidepressant activity by forced swim method and tail suspension method.

Results: The compounds were synthesized and characterized them, and the structure was confirmed. The compounds were designated as M1 to M10 depending on their substitution. The antibacterial activity was evaluated using disc diffusion test in Bacillus subtilis, Staphylococcus aureus, Pseudomonas aeruginosa, and Escherichia coli using ciprofloxacin $20 \mu \mathrm{g}$ as standard. All the 10 test drugs show significant antibacterial activity in Gram-positive organism. The antidepressant activity of novel tetrasubstituted derivatives and standard clomipramine using forced swim test and tail suspension method is evaluated in rats. Synthesized novel tetrasubstituted derivatives show a promising antidepressant activity.

Conclusion: The synthesized compounds find promising antibacterial and antidepressant activities.

Keywords: Tetrasubstituted imidazoles, Antibacterial, Antidepressant, Forced swim test, Tail suspension method.

(C) 2019 The Authors. Published by Innovare Academic Sciences Pvt Ltd. This is an open access article under the CC BY license (http://creativecommons. org/licenses/by/4. 0/) DOI: http://dx.doi.org/10.22159/ajpcr.2019.v12i10.34738

\section{INTRODUCTION}

Medicinal chemistry concerns the discovery, development, identification, and the interpretation of the mode of action of biologically active compounds at the molecular level. Emphasis is put on drugs, but the interests of medicinal chemist are not restricted to drugs but include bioactive compounds in general. Medicinal chemistry is also concerned with the study, identification, and synthesis of the metabolic products of drugs and related compounds [1].

Imidazole is a five-membered heterocyclic system with molecular formula $\mathrm{C}_{3} \mathrm{H}_{4} \mathrm{~N}_{2}$ in which the two nitrogen atoms are present at the positions 1 and 3. It is also named as 1,3-diazole. The nitrogen atom at position 1 bears a hydrogen atom and is regarded as pyrrole-type nitrogen. The second nitrogen atom at position 3 is regarded as pyridine-type nitrogen. The completely reduced form of imidazole is known as imidazolidine [2].

The imidazole ring is an important pharmacophore in modern drug discovery. Attention has been gradually more given to the synthesis of imidazole derivatives as a source of new biological agents. The imidazole derivatives are a resource for further medicinal research. The knowledge gained by various researches has recommended that substituted benzimidazoles and heterocycles, which are the structural isosteres of nucleotides, allow them to interact easily with the biopolymers, and possess pharmacological activity with lower toxicities. Changes in the imidazole structures have offered high biological activities that have proven useful for the development of new medicinal agents having improved potency and lesser toxicity. The present review highlights the various synthesized benzimidazoles and their derivatives possessing various activities such as analgesic, anti-inflammatory, anthelmintic, anticancer, anthelmintic, antioxidant, antitubercular, antiviral, antianxiety, acetylcholinesterase inhibitory, and diuretic activity [3].

Antimicrobial drugs are the greatest contribution of the $20^{\text {th }}$ century to therapeutics. Their advent changed the outlook of the physician about the power of drugs can have on diseases. Their importance is magnified in the developing countries, where infective diseases predominate. As a class, they are one of the most frequently used and misused drugs. Depression is a common and serious medical illness that negatively affects how you feel, the way you think and how you act. Major depression and mania are two extremes of affective disorders which refer to pathological changes in mood state. Major depression is characterized by symptoms such as sad mood, loss of interest and pleasure, low energy, worthlessness, guilt, psychomotor retardation or agitation, change in appetite or sleep, melancholia, and suicidal thoughts [4].

\section{METHODS}

All the reagents used are commercially available, and they are used without further purification. The synthesized compounds were mixed with previously dried $\mathrm{KBr}$ and made a disc by pressed pellet technique. Then it is placed in infrared (IR) spectrophotometer. The peaks obtained in the graph indicate different groups present in the synthesized compounds. In proton nuclear magnetic resonance (HNMR) spectroscopy the synthesized compounds are dissolved in $\mathrm{CDCl}_{3}$. This NMR spectrum reveals a different type of protons present in a compound; the standard used in NMR spectroscopy is Tetramethyl silane (TMS). Elemental analysis gives the percentage of carbon, hydrogen, nitrogen, and sulfur present in the compound. There will be a calculated percentage and experimental percentage value. The synthesized compounds are screened for their antibacterial and antidepressant activity in rats [5]. 
Synthesis of tetrasubstituted imidazole derivatives

Radziszewski synthesis of Imidazole.

It is a general method for preparing imidazole by condensation reaction of an $\alpha$-dicarbonyl compound, with aromatic substituted amine and an aromatic substituted aldehyde in the presence of ammonium acetate and glacial acetic acid at $120-140^{\circ} \mathrm{C}$ for $3 \mathrm{~h}$. The completion of reaction was checked out by thin-layer chromatography (TLC). The reaction mixture was cooled and poured into ice-cold water and neutralized with ammonium hydroxide. The precipitate was filtered washed with water and purified by recrystallizing with ethanol [6].

Scheme for the synthesis of tetrasubstituted imidazoles:

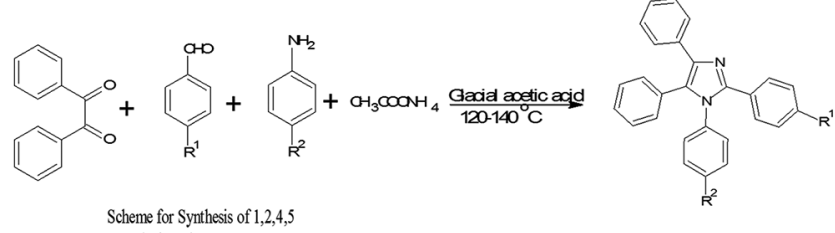

tetrasubstituted

The synthesized compounds were characterized by their physicochemical properties including nature color and solubility. Melting point was recorded on digital melting point apparatus. TLC was performed using mobile phase n-hexane:ethyl acetate (7:3), solid-phase silica gel (pre-coated TLC plate). The spots were detected using ultraviolet detection chamber. The structures of synthesized compounds were confirmed by IR, ${ }^{1} \mathrm{HNMR}$, and elemental analysis [7].

\section{Screening of activity}

Antibacterial activity by Agar disc diffusion method.

All the synthesized compounds (M1-M10) were screened for antimicrobial activity using different microorganisms. This is done by agar disc diffusion method using ciprofloxacin $(20 \mu \mathrm{g})$ as standard. Medium: Agar nutrient medium. The organisms used are Gram-positive bacteria: Bacillus subtilis and Staphylococcus aureus and Gram-negative bacteria: Pseudomonas aeruginosa and Escherichia coli [8,9]

\section{Animals used}

Albino rats (Wistar strain) and Albino mice (Swiss strain) were used to carry out the activities. The experiments were carried out as per the guidelines of CPCSEA. The animals were kept in the Animal Holding Facility of the Department of Pharmacology, Pushpagiri College of Pharmacy, Thiruvalla, Kerala. Rats were kept in grouped cages and subjected to a 12-h light:12-h dark cycle at room temperature. Animals were maintained on standard rodent chow with ad libitum access to clean tap water [10]. The animal study was performed only after obtaining approval from the Institutional Animal Ethical Committee (PCP/IAEC/2018-1/6)

\section{Acute toxicity study}

Acute toxicity studies of the synthesized compounds were carried out using OECD guideline 423. The test procedure minimizes the number of animals required to estimate oral acute toxicity. The test also allows the observation of signs of toxicity and can also be used to identify chemicals that are likely to have low toxicity.

\section{Antidepressant activity}

Forced swim method

Mice of either sex were individually forced to swim in an open cylindrical container (diameter: $0 \mathrm{~cm}$, height: $51.1 \mathrm{~cm}$ ) containing 30 $\mathrm{cm}$ of water. Treatment was given $60 \mathrm{~min}$ prior to study. All animals were forced to swim for $10 \mathrm{~min}$, and the duration of immobility was observed and measured during the final 2-min interval of the test. Each mouse was judged to immobile when it ceased struggling and remained floating motionless in water, making only those movements to keep his head above the water. A decrease in the duration of immobility is indicative of an antidepressant-like effect. Control group is treated with

Table 1: Physical data of synthesized compounds

\begin{tabular}{|c|c|c|c|c|c|c|}
\hline Compound & R1 & R2 & Mol. weight & M.P $\left({ }^{\circ} \mathrm{C}\right)$ & Yield (\%) & $\mathbf{R}_{\mathbf{f}}^{*}$ \\
\hline M1 & $4-\mathrm{OH} \mathrm{C}{ }_{6} \mathrm{H}_{5}$ & P-Bromoaniline & 467.356 & 161 & 52.28 & 0.19 \\
\hline M2 & $4-\mathrm{Cl} \mathrm{C}_{6} \stackrel{\circ}{\mathrm{H}}_{5}{ }^{3}$ & P-Bromoaniline & 485.802 & 150 & 60.90 & 0.23 \\
\hline M3 & $2-\mathrm{C}_{2} \mathrm{H}_{5} \mathrm{C}_{6} \mathrm{H}_{5}$ & P-Bromoaniline & 495.409 & 142 & 80.00 & 0.70 \\
\hline M4 & $4-\mathrm{CH}_{3} \mathrm{C}_{6} \mathrm{H}_{5}^{3}$ & P-Bromoaniline & 465.383 & 148 & 76.75 & 0.28 \\
\hline M5 & $4-\mathrm{OCH}_{3} \mathrm{C}_{6} \mathrm{H}_{5}$ & P-Bromoaniline & 481.382 & 145 & 84.74 & 0.70 \\
\hline M6 & $4-\mathrm{OH} \mathrm{C}_{6} \mathrm{H}_{5}^{0}$ & P-Fluoroaniline & 406.450 & 225 & 85.00 & 0.21 \\
\hline M7 & $4-\mathrm{Cl} \mathrm{C}_{6} \mathrm{H}_{5}$ & P-Fluoroaniline & 424.896 & 190 & 76.00 & 0.89 \\
\hline M9 & $4-\mathrm{CH}_{3} \mathrm{C}_{6} \mathrm{H}_{5}$ & P-Fluoroaniline & 404.477 & 180 & 84.15 & 0.79 \\
\hline M10 & $4-\mathrm{OCH}_{3} \mathrm{C}_{6} \mathrm{H}_{5}$ & P-Fluoroaniline & 420.477 & 189 & 73.8 & 0.57 \\
\hline
\end{tabular}

*Mobile phase for TLC of test compounds is n-hexane: ethyl acetate (7:3). TLC: Thin-layer chromatography

Table 2: Zone of inhibition of synthesized compounds (M1-M10)

\begin{tabular}{|c|c|c|c|c|}
\hline \multirow[t]{3}{*}{ Sample code } & \multicolumn{4}{|c|}{ Zone of inhibition (mm) } \\
\hline & \multicolumn{2}{|l|}{ Gram positive } & \multicolumn{2}{|l|}{ Gram negative } \\
\hline & Bacillus subtilis & Staphylococcus aureus & Pseudomonas aeruginosa & Escherichia coli \\
\hline Standard & $17 \pm 0.210$ & $16 \pm 0.333$ & $10 \pm 0.577$ & $13 \pm 0.354$ \\
\hline M1 & $2 \pm 0.200$ & $1 \pm 0.207$ & $2 \pm 0.548$ & $7 \pm 0.753$ \\
\hline M2 & $7 \pm 0.307$ & $2 \pm 0.304$ & $6 \pm 0.148$ & $5.8 \pm 0.225$ \\
\hline M3 & $9 \pm 0.333$ & $5 \pm 0.567$ & - & - \\
\hline M4 & $6 \pm 0.333$ & $5.6 \pm 0.321$ & - & - \\
\hline M5 & $5.5 \pm 0.245$ & $5 \pm 0.651$ & $5 \pm 0.785$ & $4 \pm 0.153$ \\
\hline M6 & - & - & $7 \pm 0.256$ & $8 \pm 0.845$ \\
\hline M7 & - & $1 \pm 0.459$ & $7 \pm 0.776$ & $6 \pm 0.754$ \\
\hline M8 & $1 \pm 0.376$ & - & - & - \\
\hline M9 & $5 \pm 0.600$ & $4 \pm 0.231$ & - & - \\
\hline M10 & $4 \pm 0.522$ & $4 \pm 0.742$ & $5 \pm 0.882$ & $4 \pm 0.536$ \\
\hline
\end{tabular}




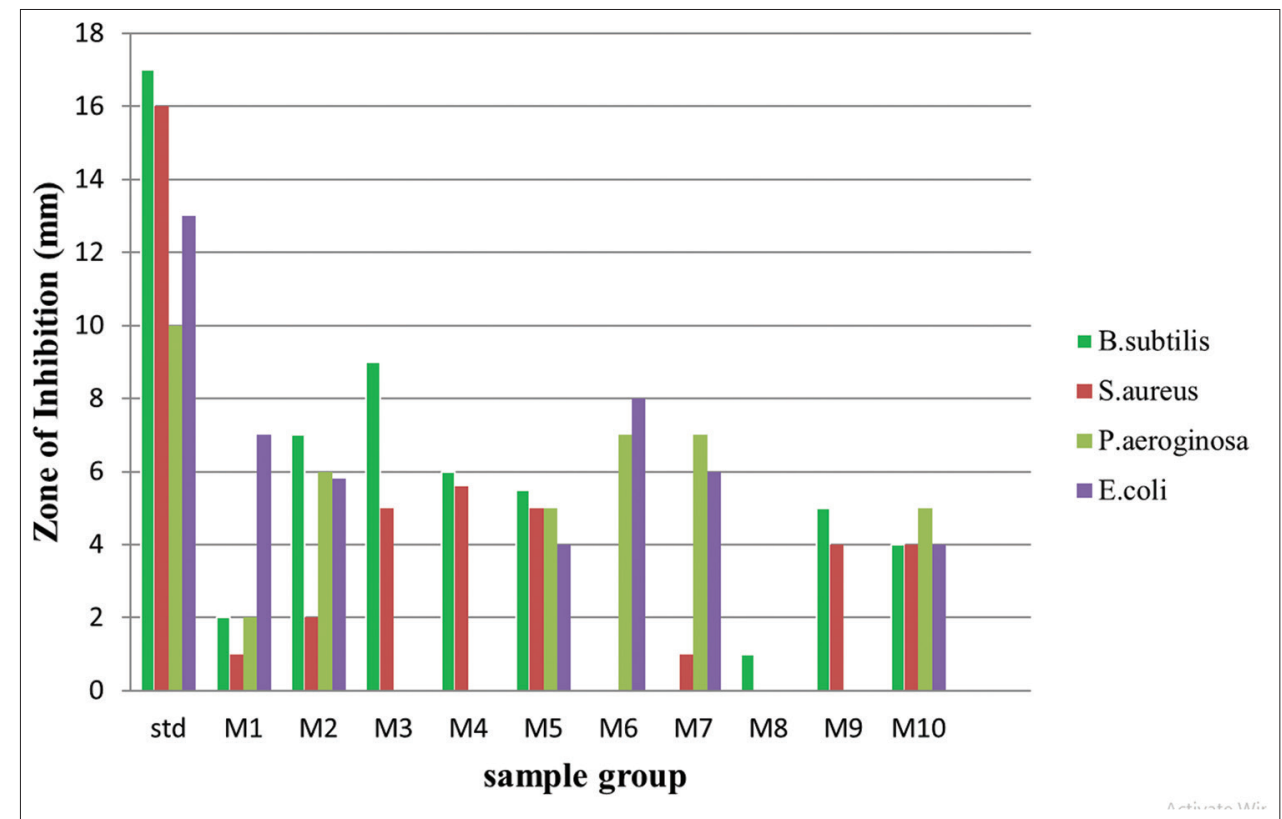

Fig. 1: Antibacterial activity of M1-M10 against Bacillus subtilis, Staphylococcus aureus, Escherichia coli, and Pseudomonas aeruginosa

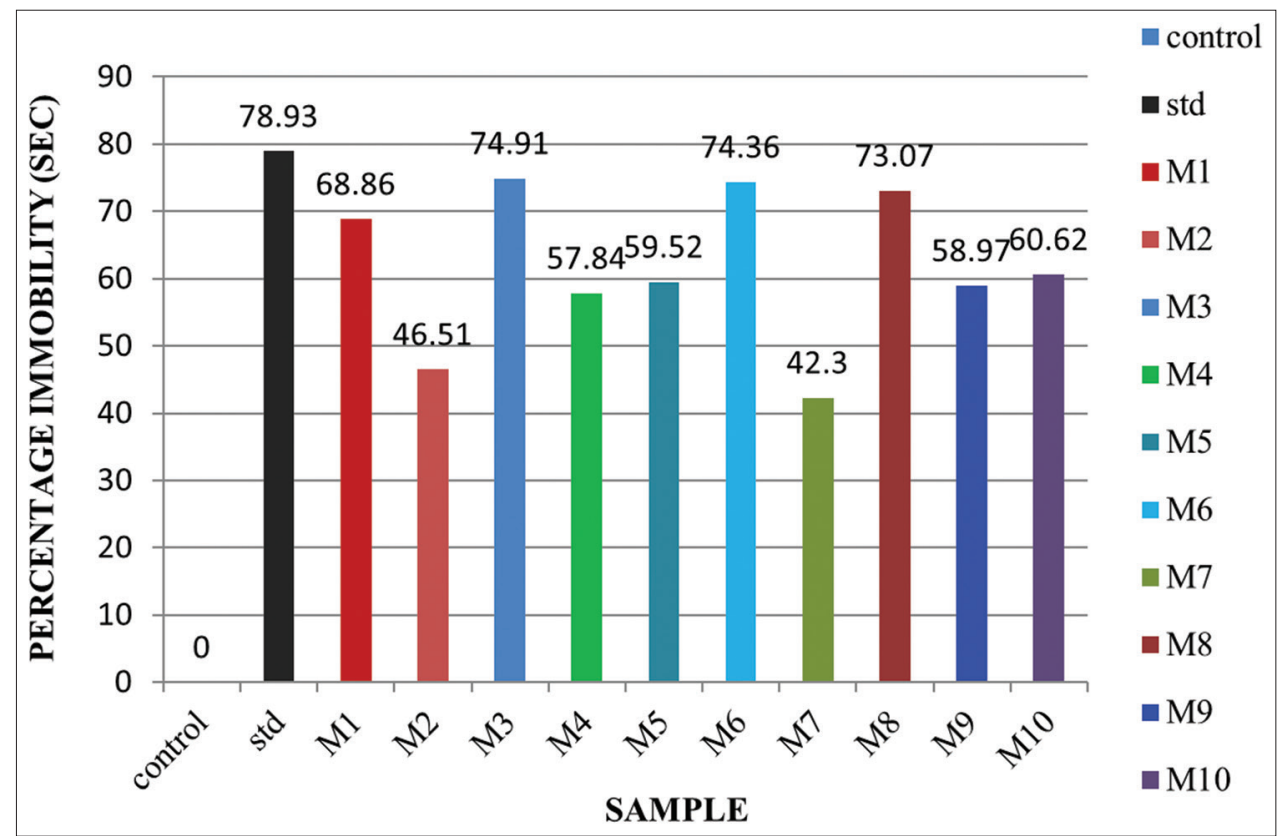

Fig. 2: Effect of M1-M10 and clomipramine in antidepressant activity in rats by forced swim test

vehicle, standard group is with clomipramine $(20 \mathrm{mg} / \mathrm{kg})$, and test group (III-XII) is with test compounds $(60 \mathrm{mg} / \mathrm{kg})[8]$.

\section{Tail suspension method}

For the tail suspension method, Wistar rats of either sex containing six animals in each group. Control group received $1 \% \mathrm{w} / \mathrm{v}$ of tween 80 p.o., standard group received clomipramine $60 \mathrm{mg} / \mathrm{kg}$ orally, and test group received (III-XII) $60 \mathrm{mg} / \mathrm{kg}$ of imidazole derivatives p.o. Treatment was given 60 min prior to the study. Rats were suspended on the edge of the table, $50 \mathrm{~cm}$ above the floor, with the help of adhesive tape placed approximately $1 \mathrm{~cm}$ from the tip of the tail. The total duration of immobility induced by tail suspension was recorded for a 6-min period. Animals were considered to be immobile when it shows any movement of the body, which hanged passively and completely motionless $[4,11]$.

\section{Statistical analysis}

Values are represented mean \pm standard error for group 6 animals. The results were analyzed by one-way analysis of variance (ANOVA), followed by post hoc Dunnett's multiple comparison test. Differences between groups were considered significant at $\mathrm{p}<0.001$ levels. This statistical analysis was carried out using GraphPad Prism 7 software.

\section{RESULTS AND DISCUSSIONS}

Physical data

The physical data such as molecular weight, melting point and Rf value of the synthesized compounds are shown in Table 1.

\section{Spectral data}

- Compound M1: 4-[1-(4-bromophenyl)-4, 5-diphenyl-1 Himidazol-2yl] phenol, IR ( $\left.\mathrm{cm}^{-1}\right) 1258.5$ (Ar-OH), 3455.7 (NH stretching), 1638.6 


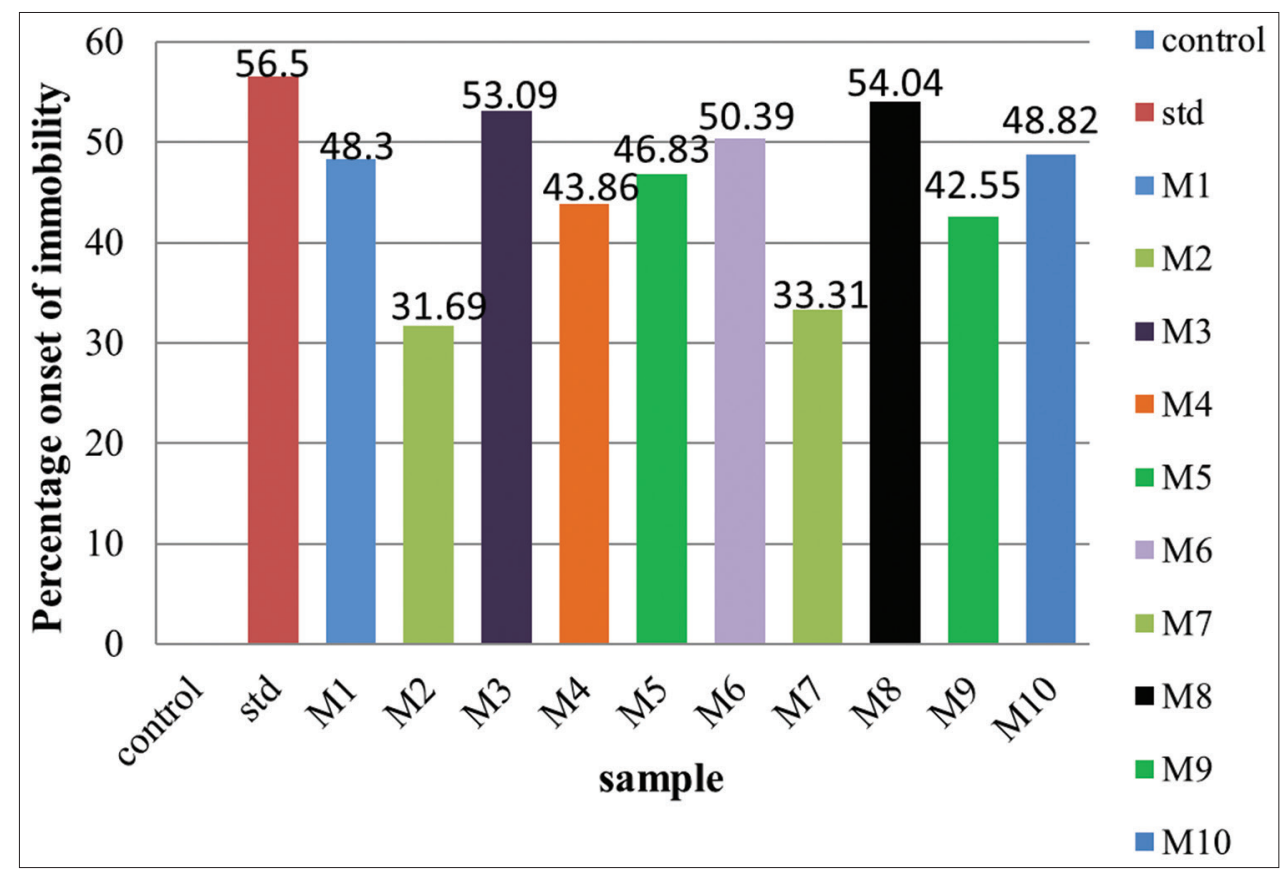

Fig. 3: Effect of M1-M10 and clomipramine in antidepressant activity in rats by tail suspension test

Table 3: Antidepressant activities by forced swim test

\begin{tabular}{llll}
\hline S. No. & Groups & $\begin{array}{l}\text { Duration of onset } \\
\text { of immobility (s) }\end{array}$ & $\begin{array}{l}\text { Percentage } \\
\text { change (\%) }\end{array}$ \\
\hline 1. & Control & $91 \pm 0.36$ & 0 \\
2. & Standard & $19.17 \pm 0.60^{* *}$ & 78.93 \\
3. & M1 & $28.33 \pm 0.3$ & 68.86 \\
4. & M2 & $48.67 \pm 0.33$ & 46.51 \\
5. & M3 & $22.83 \pm 0.30^{* *}$ & 74.91 \\
6. & M4 & $38.33 \pm 0.33^{* *}$ & 57.87 \\
7. & M5 & $36.83 \pm 0.40$ & 59.52 \\
8. & M6 & $23.33 \pm 0.42^{* *}$ & 74.36 \\
9. & M7 & $52.5 \pm 0.61$ & 42.30 \\
10. & M8 & $24.5 \pm 0.22^{* *}$ & 73.07 \\
11. & M9 & $37.33 \pm 0.33$ & 58.97 \\
12. & M10 & $35.83 \pm 0.74$ & 60.62 \\
\hline
\end{tabular}

Each value represents mean \pm standard error of the mean, $n=6,{ }^{* *} \mathrm{p}<0.001$ versus control (one-way analysis of variance followed by Dunnett's test)

Table 4: Antidepressant activity of M1-M10 by tail suspension method

\begin{tabular}{llll}
\hline S. No. & Group & $\begin{array}{l}\text { Duration of onset } \\
\text { of immobility (s) }\end{array}$ & $\begin{array}{l}\text { Percentage } \\
\text { immobility (\%) }\end{array}$ \\
\hline 1. & Control & $191.5 \pm 0.61$ & 0 \\
2. & Standard & $83.00 \pm 0.36$ & 56.65 \\
3. & M1 & $99.00 \pm 0.36^{* *}$ & 48.3 \\
4. & M2 & $130.8 \pm 0.40$ & 31.69 \\
5. & M3 & $89.83 \pm 0.20^{* *}$ & 53.09 \\
6. & M4 & $107.5 \pm 0.22$ & 43.86 \\
7. & M5 & $100.6 \pm 0.21$ & 47.46 \\
8. & M6 & $95.00 \pm 0.36^{* *}$ & 50.39 \\
9. & M7 & $127.7 \pm 0.33$ & 33.31 \\
10 & M8 & $88.00 \pm 0.36^{* *}$ & 54.04 \\
11. & M9 & $110.0 \pm 0.36$ & 42.55 \\
12. & M10 & $98.00 \pm 0.25$ & 48.82 \\
\hline
\end{tabular}

Each value represents mean \pm standard error of the mean, $n=6,{ }^{* *} p<0.001$ versus control (one-way analysis of variance followed by Dunnett's' test)

(NH bending), 696.4 (C-Br), 834.95 (para-substitution.). ${ }^{1} \mathrm{HNMR}$, $6.939(\mathrm{OH}), 7.262-8.081$ (18 Ar-H), CHN cal. \% C 69.39, H 4.10, N
5.99. Found C 67.99, H 4.80, N 6.09.

- Compound M2: 1-(4-bromophenyl)-2-(4-chlorophenyl)-4, 5-diphenyl-1 $H$-imidazole: IR $\left(\mathrm{cm}^{-1}\right) 1175.4(\mathrm{Ar}-\mathrm{Cl}), 3459.6(\mathrm{NH}$ stretching), 1638.6 (NH bending), 834.95 (para-substitution.), 696.4 (C-Br). ${ }^{1}$ HNMR 7.083-7.541 (18Ar-H).CHN cal. \%, C 66.75, H 3.73, N 5.77. Found C 66, H 4.09, N 5.01.

- Compound M3: 1-(4 -bromophenyl)-2 (2-ethoxy), 4, 5-triphenyl-1 $\mathrm{H}$-imidazole. IR $\left(\mathrm{cm}^{-1}\right) 1179.4$ (aromatic ether group), $3467.5(\mathrm{NH}$ stretching), 1638.6 (NH bending), 696.4 (C-Br). ${ }^{1} \mathrm{HNMR} 2.042-2.109$ (5H, $\mathrm{CH}_{2} \mathrm{CH}_{3}$ ), 7.092-7.643 (18Ar-H). CHN cal. \% C 70.31, H 4.68, N 5.65. Found C 63.44, H 4.06, N 5.87.

- Compound M4: 1-(4-bromophenyl)-2 (4-methyl), 4, 5-triphenyl-1 $H$-imidazole. IR $\left(\mathrm{cm}^{-1}\right) 2929.1\left(\mathrm{Ar}-\mathrm{CH}_{3}\right), 3455.7$ (NH stretching), 1634.6 (NH bending), 696.4 (C-Br). ${ }^{1} \mathrm{HNMR} 3.980-4.125\left(3 \mathrm{H}, \mathrm{CH}_{3}\right)$, 7.01-7.836 (18Ar-H).CHN cal. \% C 72.26, H 4.55, N 6.02. Found C 71.56, H 4.49, N 6.81.

- Compound M5: 1-(4-bromophenyl)-2 (4-methoxy), 4,5-triphenyl$1 \mathrm{H}$-imidazole. IR $\left(\mathrm{cm}^{-1}\right) 2842\left(\mathrm{OCH}_{3}\right), 3459.6(\mathrm{NH}$ stretching), 1642.5 (NH bending), 700.35 (C-Br). ${ }^{1} \mathrm{HNMR} 1.238-1.273\left(3 \mathrm{H}, \mathrm{CH}_{3}\right)$, 7.089-7.983 (18Ar-H).CHN cal. \% C 69.86, H 4.40, N 5.82. Found C 70.09, H 4.95, N 5.02

- Compound M6: 4-[1-(4-fluorophenyl)-4, 5-diphenyl-1 H-imidazol-2yl] phenol. IR ( $\mathrm{cm}^{-1}$ ) 1238.6 (Ar-OH), 3061.3 (NH stretching), 1610.32 (NH bending), 1457.7 (C-F), 836.5 (para-substitution). ${ }^{1}$ HNMR 6.649 (OH), 7.55-7.987 (18 Ar-H).). CHN cal. \% C 79.79, H 4.71, N 6.89. Found C 78.57, H 4.77, N 6.84.

- Compound M7: 2-(4-chlorophenyl)-1-(4-fluorophenyl)-4, 5-diphenyl-1 $H$-imidazole. IR $\left(\mathrm{cm}^{-1}\right) 1151.7$ (Ar-Cl), $3459.6(\mathrm{NH}$ stretching), 1634.6 (NH bending), 1440.6 (C-F stretching), 850.79 (Para-substitution). ${ }^{1}$ HNMR 6.942-7.582 (18Ar-H). CHN cal. \% C 76.32, H 4.27, N 6.59. Found C 74.99, H 3.08, N 5.82.

- Compound M8: 1-(4-fluorophenyl)-2, (2-ethoxy) 4, 5-triphenyl-1Himidazole. IR $\left(\mathrm{cm}^{-1}\right) 1187.3$ (aromatic ether group), 3455. $7(\mathrm{NH}$ stretching), 1642.5 ( $\mathrm{NH}$ bending), 1444.6 (C-F stretching). ${ }^{1} \mathrm{HNMR}$ 3. 970-4. $028\left(5 \mathrm{H}_{1} \mathrm{C}_{2} \mathrm{H}_{5}\right) 7.010-7.585$ (18Ar-H). CHN cal. \%C 80.16, H 5.34, N 6.45. Found C 81.97, H 5.92, N 7.21.

- Compound M9: 1-(4-fluorophenyl)-2 (4 methyl), 4, 5-triphenyl-1Himidazole. IR ( $\mathrm{cm}^{-1}$ ) 3388.4 (NH stretching), 1632.6 (NH bending), 1440.6 (stretching). ${ }^{1} \mathrm{HNMR} 2.0442 .315\left(3 \mathrm{H}, \mathrm{OCH}_{3}\right) 7.004-7.590$ (18Ar-H). CHN cal. \% C 83.14, H 5.23, N 6.93. Found C 80.21, H 3.91, N 5.21. 
- Compound M10: 1-(4-bromophenyl)-2 (4-methoxy), 4, 5-triphenyl$1 H$-imidazole. IR $\left(\mathrm{cm}^{-1}\right) 3443.8$ ( $\mathrm{NH}$ stretching), $1642.5(\mathrm{NH}$ bending), 1424.8 (C-F stretching). ${ }^{1} \mathrm{HNMR}$ 2.119-3.782 $\left(3 \mathrm{H}, \mathrm{CH}_{3}\right)$, 6. 990-7.585 (18Ar-H). CHN cal. \% C 79.98, H 5.03, N 6.66. Found C 79.41, H 5.66, N 7.00.

\section{Antibacterial activity}

All the synthesized compounds were screened for their antibacterial activity and the graphical representation is shown in Fig. 1 and the zone of inhibition is tabulated in Table 2. Among them M2, M3 and M9 shows significant activity in Bacillus subtilis. M6 have no significant activity in gram positive organism.

\section{Acute toxicity study}

Acute toxicity study of the synthesized compounds was conducted as per OECD guidelines 423 in Swiss albino rat. The compounds showed toxic effect at a dose of $2000 \mathrm{mg} / \mathrm{kg}$. Hence, the safe dose of the drug is $300 \mathrm{mg} / \mathrm{kg}$.

\section{Antidepressant activity}

Forced swim test

Synthesized 10 compounds were evaluated for their anti-depressant activity by forced swim test. The results obtained is shown in Fig. 2 and the values obtained are tabulated in Table 3. M3, M6 and M8 shown significant activity when compared with standard.

\section{Tail suspension method}

The datas obtained by tail suspension method is graphically represented in Fig. 3 and tabulated in Table 4. Compounds M3, M6 and M8 shows significant activity.

\section{DISCUSSIONS}

Novel tetrasubstituted imidazole derivatives were tested for in vitro antibacterial activity against both Gram-positive $(B$. subtilis and $S$. aurous) and Gram-negative bacteria (P. aeruginosa and E. coli). Synthesized compounds showed activity against Gram-positive bacteria and Gram-negative bacteria. Compounds M3 and M2 showed significant activity against B. subtilis. Compounds M5 and M3 show activity against $S$. aureus. M7 and M6 show significant activity against $P$. aeruginosa. M6 and M7 show the highest activity against $E$. coli. All the synthesized compounds were compared with the standard drug ciprofloxacin $(30 \mathrm{mcg})$. The synthesized compounds show significant activity against Gram-negative organisms.

All the compounds are tested by forced swim test and tail suspension method for their antidepressant activity. Of the ten synthesized compounds, M1, M4, M6, and M9 show significant activity in forced swim test method and M1, M3, M6, and M8 show antidepressant activity by tail suspension method. Hydroxy-substituted tetrasubstituted imidazole shows greater antidepressant activity.

\section{CONCLUSION}

Compounds with electron donating group at ortho position have significant activity on gram positive organism when compared with other electron donating groups at para position. Anti depressant activity by observed compound may be due to electron donating group at ortho position of imidazole nucleus.

\section{ACKNOWLEDGMENT}

We are thankful to STIC Cochin University, Kerala, for recording the CHN data; VIT University, Chennai, for recording the IR and NMR spectra; and Pushpagiri College of Pharmacy, Thiruvalla, for the animals provided.

\section{AUTHOR'S CONTRIBUTION}

Mr. Akshay Murali is the scientific leader in the synthesis of biologically active derivatives of tetrasubstituted imidazole and actively participated in the synthetic part of the study. In addition to this, he contributes an immense effort for the structural elucidation of the synthesized compounds. Ms. Anusha Shaji is the direct executor of the study of antidepressant activity of newly synthesized compounds and played an important role in obtaining results on antidepressant activity.

\section{CONFLICTS OF INTEREST}

The authors report no conflicts of interest.

\section{REFERENCES}

1. Agarwal OP. Organic Chemistry Reaction and Reagent. 34 th ed. Weinheim: Wiley-VCH; 2002. p. 826-8.

2. Kunied T, Mutsanga H. The Chemistry of Heterocyclic Compounds. Palmer: Academic Press; 2002. p. 175.

3. Prasad PM, Kanvinde AS, Raja S. Potent biological agent benzimidazole a review. Int J Pharm Pharm Sci 2016;8:22-3.

4. Chowdhury A, Juvekar AR. Antidepressant and nootropic activity of aqueous extract of Indigofera tinctoria in mice. Int J Pharm Pharm Sci 2014;6:131-5.

5. Tripathy KD. Essential of Medical Pharmacology, $5^{\text {th }}$ ed, New Delhi: Jaypee Brothers Medical Publishers; 2003. p. 627-32, 369-70, 405-7.

6. Jawaharmal S, Lamba HS, Narwal S, Singh G, Saini DR, Kaur A, et al. Synthesis of novel imidazole compounds and their anti-microbial evaluation. Indo Glob J Pharm Sci 2012;2:147-56.

7. Mariappan G, Alam S, Sutharson L, Haldar PK, Nath S. Design synthesis and neuropharmacological activity of dihydro imidazole derivatives. Indian J Chem 2013;52B:568-72.

8. Hadizadeh F, Hosseinzadeh H, Motamed-Shariaty VS, Seifi M, Kazemi SH. Synthesis and antidepressant activity of n-substituted imidazole-5-carboxamides in forced swimming test model. Iran $\mathbf{J}$ Pharm Res 2008;7:29-33.

9. Parab RH, Dixit BC. Synthesis characterization and anti-microbial activity of imidazole derivatives based on 2-chloro-7-methyl-3formylquinoline. J Chem 2012;9:1188-95.

10. Mishra R, Ganguly S, Sethi KK, Mazumder PM. Synthesis and anticonvulsant activity of some novel 2-methyl imidazole derivatives. Lett Drug Des Discov 2012;9:402-8.

11. Khaliullin F, Nikitina I, Valieva A, Miftakhova A, Khalilov L, Mescheryakova E. Synthesis and antidepressant activity of 2-bromo-1(thietan-3-yl) imidazole 4, 5-dicarboxylic acid derivatives. Int J Pharm Pharm Sci 2017;9:154. 